\title{
Frequency, duration, and speed of wheel running of rats as a function of age and starvation*
}

\author{
LEONARD F. JAKUBCZAK \\ Gerontological Psychology Research Laboratory, VA Hospital, St. Louis, Missouri 63125
}

\begin{abstract}
The purpose of this experiment was to determine whether age differences in amounts of wheel running of starved rats were due to the frequency of bursts of running, to the average duration of bursts, to speed, or to any combination of these parameters. The experiment was carried out according to a 3 by 2 by 2 mixed model design. The independent variables were age $(67,293$, and 746 days old at the start of starvation), food deprivation (total starvation vs ad lib), and occasion of measurement (initial vs maximum activity). The dependent variables were number of wheel revolutions, number of bursts of activity, number of seconds of running per burst, and revolutions per second. The results indicated that acutely starved rats run more often, for longer periods, and at higher speeds than do sated rats, and that with increased age rats run less often, for a shorter time, and at slower speeds.
\end{abstract}

The purpose of this experiment was to determine whether age-dependent decrements in the amounts of daily wheel running of starved rats were due to differences in the frequency of bursts of running, to differences in the average duration of running, to differences in the speed of running, or to differences in any combination of these parameters. With increasing weight loss, the amount of wheel running of young starved rats increases to a maximum and then decreases shortly before death (Campbell, 1964). This pattern of running changes only quantitatively with increasing age. A previous experiment (Jakubczak, 1967) indicated that, independent of drive level, amounts of wheel running of starved rats decrease with increasing age. In that investigation, the cumulative total of wheel running of starved rats decrease with increasing age. In that investigation, the cumulative total of wheel revolutions during $24 \mathrm{~h}$ was used as the dependent variable. However, rats do not run continually during the 24-h period, but distribute their running in a number of episodes or bursts of running (Slonaker, 1912). More recently, Premack and Schaeffer (1963) found that during a 1 -h sample of running, starvation increases the cumulative amount of wheel running of rats by increasing both the frequency and average duration of bursts of running, but has little effect on speed of running. Consequently, the age differences in the amounts of wheel running of starved rats (Jakubczak, 1967) may have been due either to differences in the

\footnotetext{
*This research was supported by 821 funds of the U.S. Veterans Administration. Preliminary reports of this research were presented at the American Psychological Association Convention in Washington, D.C., 1970, and to The Gerontological Society Meeting, Houston, Texas, 1971. Thanks to Dr. Gary Burger, St. Louis University, and Dr. John F. McCoy, Chief, Southern Research Support Center, North Little Rock, Arkansas, for the statistical consultation and analysis, and to Judith Reynolds Keenan and Vern McIntosh for data collection and reduction.
}

frequency of bursts of running, to differences in the average duration of bursts, to differences in speed of running, or to differences in any combination of these parameters. A precise location of the source or sources of age differences in the total amount of running of starved rats should result in more specific hypotheses about the mechanisms underlying these age differences than is possible with the traditional drive-habit distinction.

\section{METHOD}

\section{Design}

The experiment was carried out according to a 3 by 2 by 2 mixed model design (Winer, 1971, Case II). The independent variables were age $(67,293$, and 746 days old at the start of starvation), food deprivation (total starvation vs ad lib), and occasion of measurement (initial vs maximum activity). The dependent variables were number of wheel revolutions, number of bursts of activity, number of seconds of running per burst. and revolutions per second.

\section{Procedure}

Forty-eight male Sprague-Dawley (Charles River) rats were assigned randomly to Wahmann activity cages (LC-34) and to the food-deprivation conditions within each age group ( 8 per subgroup). However, because of either mortalities or equipment failure, the number of rats in the respective subgroups were: $67 \mathrm{E}-7,67 \mathrm{C}-5,293 \mathrm{E}-6,293 \mathrm{C}-7,746 \mathrm{E}-5,746 \mathrm{C}-6$. The frictional torque was equalized among the whecls at approximately $.003 \mathrm{ft}$ lb (Lockard, 1965). The rats were adapted to the activity cages for 24 days, during which time they were fed Purina rat pellets and water ad lib. The door between the living compartment and the drum remained open daily for $22 \mathrm{~h}$. During the remaining $2 \mathrm{~h}$ (starting at 1:00 p.m.), the rats were locked in their living compartments. These $2 \mathrm{~h}$ were used to determine and record body weights and wheel revolutions of the rats and to maintain the equipment. At the end of the adaptation period, food was totally withdrawn from the rats of the starvation subgroup of each age group. The starvation was continued from 5 to 18 days until the rat had lost $35 \%$ of its initial weight, at which time food again was made available. The previous study (Jakubcrak, 1967) had indicated that, regardless 


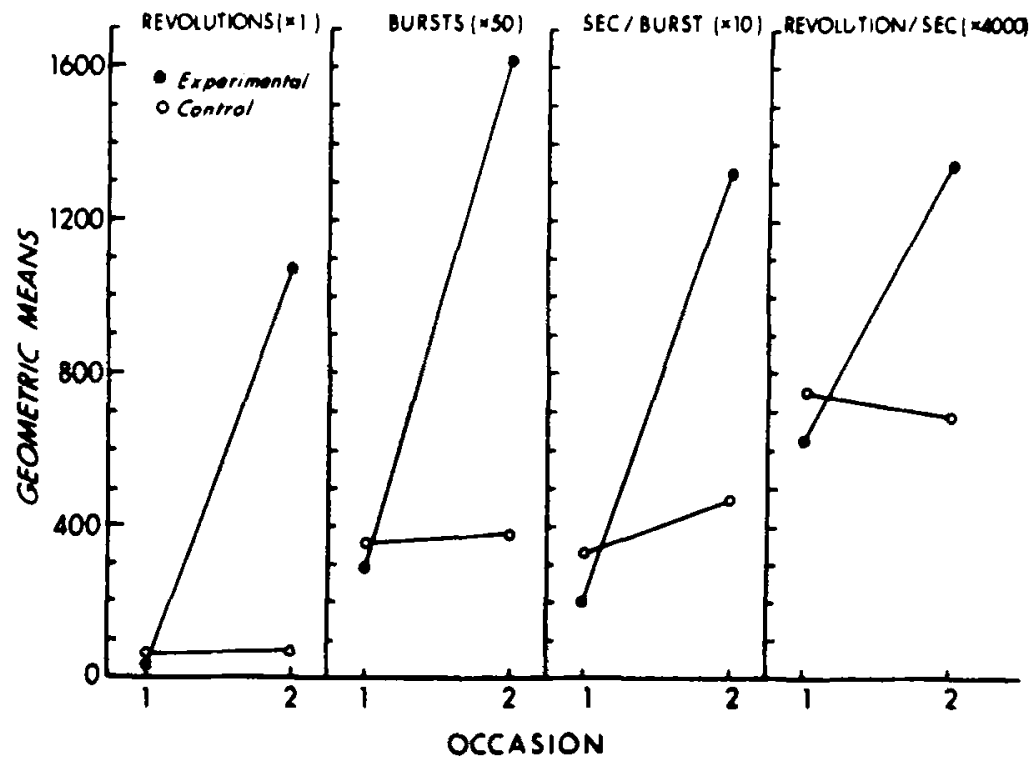

Fig. 1. Geometric means of revolutions, bursts, sec/burst, and revolutions/sec as a function of food deprivation and occasion of measurement, averaged across age. Note differences in scale among measures.

of age. $35 \%$ body weight loss constitutes approximately $90 \%$ of total survival time during starvation. The laboratory lights were turned on automatically between 6:00 a.m. and 6:00 p.m. The temperature of the laboratory during the food deprivation was regulated at $72^{\circ} \mathrm{F}$, and the relative humidity varied between $35 \%$ and $45 \%$.

The distribution of activity over each $22-\mathrm{h}$ period was recorded by Esterline Angus operations recorders (Model $A W$ ), using a chart speed of $3 / 4 \mathrm{in} . / \mathrm{min}$. Records were made daily throughout the entire experiment. Each revolution of the wheel moved the arm of the Veeder counter up and down, thus opening and closing a sensitive miniature switch (Model CTMLD-0102, Robertshaw Controls Co.. Columbus, Ohio) and activating a pen on the recorder. In order to analyze the initial levels of activity, the 5 days prior to food deprivation were examined and the graphic record of the day on which a particular rat's median wheel revolutions occurred was analyzed with respect to burst frequencies and durations. In order to analyze the maximum levels of activity of food-deprived rats, the graphic record of the day on which each food-deprived rat's maximum wheel revolutions occurred was similarly analyzed. Finally, in order to analyze the "maximum" activity of the control rats during the deprivation period of their experimental counterparts, the graphic record of the day within the appropriate range of days on which each control rat's median wheel revolution occurred was analyzed as above. A burst of running was defined as a collection of one or more revolutions (pen excursions) separated by less than $60 \mathrm{sec}$ from any preceding response. Burst duration was defined as the sum of durations of bursts in seconds to the nearest $10 \mathrm{sec}$, divided by the number of bursts.

The speed of revolution (revolutions/sec) could not be determined from the Esterline-Angus records because of the slow paper speed that was required to record for $22 \mathrm{~h}$. However, the average speed of revolutions was derived by dividing total revolutions by total seconds of running.

The values of each variable were transformed into $\log (1+X)$ equivalents in order to meet the assumption of homogeneity of variance. Each set of data was analyzed by a modified unweighted means analysis of variance (Winer, 1971, Case II; Huitson, 1966). The magnitude of experimental effects was estimated by computation of $\omega^{2}$ (Vaughan \& Corballis, 1969).

\section{RESULTS}

The Age by Deprivation by Occasion interaction was not significant for any of the four variables. Thus disregarding age, there was, as Fig. 1 indicates, a significant increase in revolutions between the two occasions of measurement under food deprivation, while $\mathrm{ad}$ lib feeding produced no change $(\mathrm{F}=29.77, \mathrm{df}=1 / 28$, $\mathrm{p}<.01)$. This increase was associated with significant increases in bursts, sec/burst, and revolutions/sec under food deprivation $(F=33.57,6.84$, and $13.55, p<.01$, .05 , and .01 , respectively, $\mathrm{df}=1 / 28$ ). In the analyses of variance, the proportion of the within-Ss variance due to the Deprivation by Occasion interaction was $21 \%, 15 \%$, $6 \%$, and $13 \%$ for revolutions, bursts, sec/burst, and revolutions/sec, respectively.

Disregarding deprivation and occasion, there was a significant decrease in revolutions with increasing age ( $F$ $=32.40, \mathrm{df}=2 / 28, \mathrm{p}<.01)$. This decrease in revolutions was associated with significant decreases of bursts, $\mathrm{sec} /$ burst, and revolutions/sec as a function of age $(\mathrm{F}=$ $22.47,18.75$, and 11.60 , respectively, $\mathrm{df}=2 / 28$, $\mathrm{p}<.01$ ). On all measures, the youngest group was significantly higher than the other age groups that did not differ between themselves (Fig. 2). The effects of age grouping on revolutions, bursts, sec/burst, and revolutions/sec in each of the four analyses of variance accounted for $44 \%, 35 \%, 33 \%$, and $22 \%$ of the between-Ss variances, respectively.

Finally, there were no significant differences among the age groups with respect to the relative weight at which maximum activity occurred: $26 \%, 28 \%, 26 \%$ (in order of age).

\section{DISCUSSION}

The results indicated that the increase in the total amount of running of starved rats in activity wheels is associated with increases in the frequency and the average duration of bursts of running, as well as the speed. The results are, in part, consistent with those of 
Fig. 2. Geometric means of revolutions, bursts, sec/burst, and revolutions/sec as a function of age, averaged across food deprivation and occasion of measurement. Note differences in scales among measures.

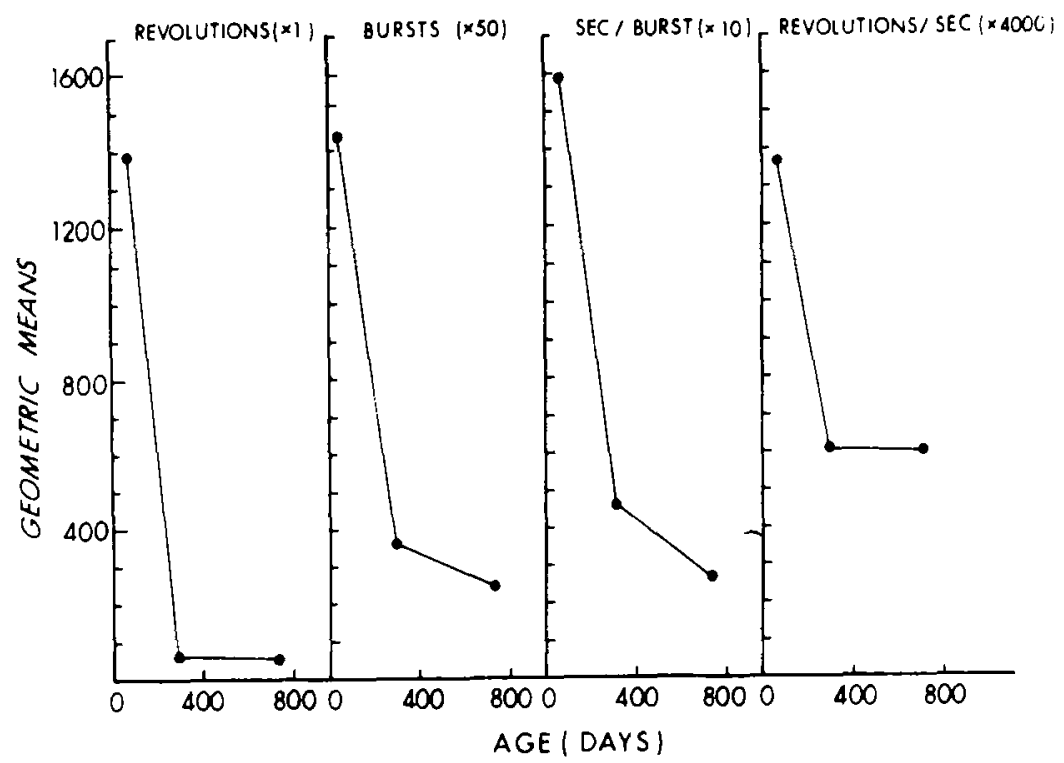

Premack and Schaeffer (1963), who found that $23 \mathrm{~h}$ of starvation increased the total amount of activity wheel running of rats during a 1-h sample by increasing both the frequency and average duration of bursts of running, but had little effect on speed of running. The discrepancy with respect to speed may be due to procedural differences between the two studies, such as degree of food deprivation, duration of observation, measurement of speed, etc. Nevertheless, the two studies taken together indicate that acutely starved rats run more often, for longer times, and perhaps at higher speeds than do sated rats. In contrast, Campbell and Lynch (1967) found that 46 days of starvation increased the number of revolutions per burst, but not the frequency or the duration of bursts. This discrepancy probably is due to differences in the definition of a burst between the two sets of studies. Several bursts, as defined in the study by Premack and Schaeffer (1963) and in the present study, could have been included in one burst as defined by Campbell and Lynch (1967). ${ }^{1}$ Thus, the definition of burst is critical in studies of activity.

The results also indicate that the decrease in wheel running with increasing age is associated with decreases in the frequency and average duration of bursts of running as well as speed. These results are consistent with those of the previous study (Jakubczak, 1967), in which equal increments in weight loss produced increments in running that were proportional to the age differences in initial levels, and they extend the previous findings to other parameters of running. The age-related decrements in the frequency and average duration of bursts of running and speed were probably due to differences in nondrive mechanisms that underlie running, since the three age groups lost the same percentage of weight between the initial and maximum levels of running and since the degree of drive that results from starvation is proportional to relative weight loss regardless of age (Campbell, Teghtsoonian, \& Williams, 1961; Williams \& Campbell, 1961; Jakubczak, 1967; Collier, 1969). The decrease in the frequency of bursts with increasing age represents an increase in the duration of pauses between bursts of running, since the frequency of bursts and the duration between bursts of running are inversely related (Premack \& Schaeffer, 1963). Thus, with increasing age, the rat runs at slower speeds, for a shorter time, and pauses longer. This pattern of differences may be due to age-related decrements in speed of responding, resistance to fatigue, and recovery from it. Such age-related decrements were observed in swimming rats (Birren \& Kay, 1958). Alternatively, since a running burst may terminate whenever levels of free fatty acids exceed a certain value (Collier \& Hirsch, 1971), the age-related decrease in burst frequency and duration may be due to age-related increases in levels of free fatty acids and decreases in the rate of their metabolism. Further research is needed to specify the mechanisms of these age differences in running.

\section{REFERENCES}

Birren, J, E., \& Kay, H. Swimming speed of the albino rat: Age and sex differences. Journal of Gerontology, 1958, 13, 374-377.

Campbell, B. A. Theory and research on the effects of water deprivation on random activity of the rat. In M. J. Wayner (Ed.), Thirst. New York: Macmillan. 1964. Pp. 317-334.

Campbell, B. A., Teghtsoonian, R., \& Williams, R. A. Activity, weight loss, and survival time of food-deprived rats as a function of age. Journal of Comparative \& Physiological Psychology, 1961, 54, 216-219.

Campbell, B. A., \& Lynch, G. S. Activity and thermoregulation during food deprivation in the rat. Physiology \& Behavior. 1967, 2, 311-313.

Collier, $G$. Body weight loss as a measure of motivation in hunger and thirst. Annals of the New York Academy of Sciences, 1969, 157, 594-609.

Collier. G.. \& Hirsch. E. Reinforcing properties of spontaneous 
activity in the rat. Journal of Comparative \& Physiological Psychology. 1971, 77. 155-160.

Huitson, A. Analy'sis of variance. New York: Hafner, 1966. P. 21.

Jakubczak, L. F. Age differences in the effects of terminal food deprivation (starvation) on activity, weight loss, and survival of rats. Journal of Gerontology, 1967, 22, 421-426.

Lockard, R. B. Some methodological factors in activity wheel research. Perceptual \& Motor Skills, 1965, 20, 1133-1138.

Premack, D., \& Schaeffer, R. W. Distributional properties of operant-level locomotion in the rat. Journal of the Experimental Analysis of Behavior, 1962, 5, 89-95.

Premack. D., \& Schaeffer. R. W. Some parameters affecting the distributional properties of operant-level running in rats. Journal of the Experimental Analysis of Behavior, 1963, 6, $473-475$.

Slonaker, J. R. The normal activity of the albino rat from birth to natural death, its rate of growth and the duration of life.
Journal of A nimal Behavior, 1912, 2, 20-42.

Vaughan, G. M.. \& Corballis, M. C. Beyond tests of significance: Estimating the strength of effects in selected ANOVA design. Psychological Bulletin, 1969, 72, 204-213.

Williams, R. A., \& Campbell, B. A. Weight loss and quinine-milk ingestion as measures of "hunger" in infant and adult rats. Journal of Comparative \& Physiological Psychology, 1961, 54, 220-222.

Winer, B. J. Statistical principles in experimental design. New York: McGraw-Hill, 1971.

(Received for publication March 24, 1972; revision received August 31, 1972.)

\section{NOTE}

1. Revolutions/burst were derived from the data of the present experiment and analyzed. Age decreased and starvation increased revolutions/burst. 